\title{
Government Administrative Control Tow er in Crisis Management System: Definition, Issues, and Policy Implications
}

\author{
Dalgon Lee*
}

\begin{abstract}
A number of scholars and media in South Korea have recently raised questions regarding the necessity of a "government administrative control tower" (GACT) for dealing with crises. This paper aims to conceptualize GACT as a crisis management system and suggests administrative methods for improving this model by examining issues raised by its operation. Since the control tower is critical in times of crisis, this paper limits its focus to the role of GACT as a crisis management control tower. In crisis, an on-site control tower focuses especially on prevention, and on-site response and management must be synchronized with a higher-level administrative decision making control tower for the system to operate properly. While a fully authorized on-site control tower should serve as the central agent, a higher-level administrative decision making control tower should mobilize additional organizations and resources to support on-site capability. The operating principle for the latter should be to create an environment in which heterogeneous parties work together to make decisions about what to do rather than the president or the prime minister directly making orders and taking control.
\end{abstract}

Keywords: control tower, crisis management, system of collaboration

\section{INTRODUCTION}

South Korea is often called a dangerous society, and the accident level is indeed high. In last five years, over 1.45 million human accidents have occurred, and in 2013 alone, over 290 thousands accidents caused 7,147 deaths and left 359,000injured (Ministry of Public Safety and Security, 2014). The sinking of the ferry ship Sewol and recent outbreak of MERS caused serious damage to not only South Korean society but

* Dalgon Lee is a professor of public policy at Gachon University. E-mail: dalgon@ gachon.ac.kr.

Manuscript received December 4, 2015; out for review December 10, 2015; review completed December 17, 2015; accepted December 17, 2015.

The Korean Journal of Policy Studies, Vol. 30, No. 3 (2015), pp. 125-145.

(C) 2015 by the GSPA, Seoul National University 
also its economy, ultimately weakening the government's ability to execute state affairs. There are reports estimating that MERS alone caused economic damage in the range of $\mathbf{W} 1$ quadrillion.

Whenever large-scale disasters have occurred, the government administrative control tower (GACT) has been front and center. Considering that administrative democracy and the decentralization of power are key values of the Korean government, it is interesting how frequently undemocratic terms like "central control" and "tower," which evoke a highly concentrated authority, are used during crises. The Korean media mostly use the phrase "control tower" to criticize the president's or prime minister's inability to effectively respond to crisis. Simultaneously, most on-site control towers find themselves unable to systematically prevent and respond to crises following the crisis management manual or based on information on the ground.

There are also voices strongly advocating the necessity of control towers in policy and administration in general, not just in connection with crisis management. More specifically, scholars argue that the merger between two government organizations or the creation of a new one requires a control tower to oversee the new department's tasks. For example, when Ministry of Science and Technology merged with Ministry of Education, scholars and the media argued for the establishment of a control tower to execute national level science and technology policies, and need for an information technology control tower arose when Ministry of Information and Communication restructured itself. Debate surrounding the establishment of the Ministry of Oceans and Fisheries also led to calls to install a control tower.

The prevailing reasoning behind these calls for control towers was that if a specific field's functions and tasks are scattered around different departments, the possibility of repeated effort and difficulties in communication arises. This reasoning could ultimately lead to the establishment of a new minister-level department and to the writing of fundamental laws that lay the foundation for a specific field as a whole (Kim, 2008; Park, Ko, \& Kim, 2012; Kim, 2011).

On the other hand, there are issues that require a national response in the long term but that are currently classified as low priority and that therefore do not receive attention. The aging population, unemployment, job creation, land usage, and restricted development area (greenbelt) are prime examples of such issues. Control towers are also needed to develop new policies, eliminate redundancy among departments, do away with outdated policies, clarify aimless and confusing policies, remove unnecessary departments, and guard against subsidies that are a hotbed for corruption. In the case of redundant tasks and drifting policies, administrative control towers different in nature and content from crisis management control tower are needed, so separate research should be conducted to properly address it. 
This paper is the first result of a series of studies on the idea of a government administrative control tower, and discussion in it is limited to the use of control towers as a crisis management system. In a crisis, a supervising system with centralized control should be in place to coordinate what needs to be done following early warning and response. Although on-site management capability is the deciding factor in the success or failure of crisis management, as the decision-making process climbs up the ladder, it requires a control tower of a different nature. The ability to share information on the ground, along with high degree of professionalism, is required to make quick decision making possible. Who is in the top control tower and where it is located are critical factors.

\section{THE CONTROL TOWER CONCEPT NARROWLY AND BROADLY DEFINED}

The control tower idea as it is often used in the mainstream media is an engineering technology concept, not an academic concept in administration science. In engineering technology, the term designates a central hub at the top of a tall building used in aviation from where controllers with a high level of authority direct takeoff and landing. It also is used to refer to command posts used in military operations and shooting ranges: these central command units have the highest authority within their jurisdiction and direct and control resources following a strict plan.

The control tower concept is also used in supply chain management, which is a process of making decisions and execution them by visualizing distribution flow with real time data (Bentz, 2014). Such systems rely on technology, the utilization of both data and information, and a step-by-step decision-making process. To optimize the system, decision making is also carried out in a cloud system, where hypothetical problems are analyzed and shared.

The control tower concept can be applied in national policy, especially to the process of establishing and employing control towers in times of crisis. In administration, the control tower is narrowly defined as a systematic method whereby a central organization controls a situation by directing certain individuals to act as planned, agilely adjusting its approach in the face of uncertainty and the ever-present possibility of expanding disaster. On-site control towers can take many organizational forms, according to types of accidents (Kang and Park, 2014), and higher decision-making control towers can be linked to on-site management. In certain cases, the president can function as such a control tower, and organizations that work to solve internal problems among themselves can be seen as consulting control towers. 
A fully developed idea of the control tower would be a system through which decisions about how to respond to a situation are made and implemented via organizations that are linked together and that include on-site organizations, high-level decisionmaking organizations, nongovernmental organizations, and local organizations. A control tower is essentially a group of organizations that form the shape of a pyramid, in which each organization has its own roles and tasks. The highest control tower integrates many on-site control towers; it makes decisions based on information on the ground in different phases of the operation; it directs operations, issues commands, and sets limits on what actions are permissible. One could make the concept even more broadly applicable by establishing principles, standards, and laws, and by developing an international cooperation system for preparing, responding, and managing crises and for methods of preventing them as well. This is broader term for control tower as it could include post management and policy changes in administrative aspect.

Unless otherwise specified, I draw on this extended idea of the control tower and keep the focus on structure and process. In a more academic approach the term "control system" rather than "control tower" would be used, since the idea refers to systematic cooperation among many organizations to manage a crisis. However, the term "control tower" still connotes the idea of systematic relationship among components from the top to bottom.

\section{ON-SITE AND ADMINISTRATIVE CONTROL TOWERS}

On-site management organizations and higher-level organizations supplying resources not securable on-site while overseeing the entire operation carry out their tasks according to different principles. Although both are tightly linked, the on-site crisis management system is grounded in execution, while administrative organization is concerned with reasoning and making decisions.

On-site control systems are affected by different types of threats that take place under various conditions and surroundings with different sorts of potential victims and are characterized by specific response procedures, organizational capabilities, methods of internal communication and cooperation, and types and levels of commanders. The extent to which an on-site control tower follows the response manual, the training level and morale of the response team, and the quality level of the control system also affects performance. In the event of sudden disasters, warning, evacuation, emergency medical service, SAR (search and rescue), and emergency recovery should be simultaneously and rapidly executed.

The administrative control system makes the major decisions about what actions 
should be taken by the on-site control system. Its major tasks are professional assessment, enhancing local and civil cooperation, and supplying resources that are outside each of the on-site control tower. Media, public opinion, and political actors also play a major role in control systems. Such organizational activities are responsible and regulated by not only the constitutional laws but also government organization laws and other related regulations.

\section{CLASSIFICATION OF ACCIDENTS AND CRISES}

Accidents and crises that may require a control tower include the war on terrorism, crises in specific locations (airspace, ground, underground, and on the sea), infectious disease outbreaks and health threats such as harmful GMOs, nuclear power facility accidents, cyberattacks on information and communication networks, and serious malfunctions of utilities and infrastructure such as water supply, gas, and the power grid.

All of these crises pose a serious safety threat and cause panic and chaos, and their resolution tends to be uncertain. These ways of characterizing crises are very different from the way they are classified in academic research and in crisis management theory (WEF's Global Risk 2015 lists 28 causes of global crises, classifying them as either societal economic, environmental, geographic, or technological in nature). However, describing them in such a way makes them more amenable to being understood in terms of the more expansive idea of the control tower, since on-site control systems and higher-level administrative decision-making systems are inseparable in reality. Both systems are closely connected and hinge on agility and austerity in action. Both systems should be prepared to execute robust response measures (respecting the basic rights of the people) and should be subject to a strict hierarchy that does not obtain in peacetime (Seidman, 1998, p. 142). These two types of control towers acknowledge the severity, uncertainly, intensity and pressure of a given crisis and recognize the urgent need to make decisions in identical manner, but the tasks they execute are different in nature.

\section{ON-SITE CONTROL TOWER PROBLEMS AND SOLUTIONS}

\section{On-Site Response Capability}

When it comes to responding to crises, on-site response is paramount, especially when it comes to responding to crises in specific locations. Prevention is the best 
solution possible, and it is also crucial to building organizations with the ability to prepare for and respond to crises. Each organization should execute warning missions in which they monitor and assess potential threats. The quality of the personnel that make up organizations involved in crisis management, including those composed of civilian and voluntary groups with first response capability, and the attitude of this personnel toward a given crisis are driving forces in overcoming it. Acquiring proper equipment and ensuring that the members of a rescue team are receiving high-level training is crucial.

The problem of hydrofluoric acid leakage at Gumi in 2012 was initially approached without a proper understanding of hydrofluoric acid compounds. Crisis management analysis of sea accidents from the sinking of the ferry ship Namyoung in 1970, the sinking of a ferry in the West Sea in 1993, an oil spill near Taean in 2007 to the recent sinking of ferry ship Sewol revealed that vastly inadequate first response capability was the most urgent problem at hand in all cases (Ryu, 2007). In case of Sewol, mobilization itself was the problem owing to a lack of information and a lack of organization with respect to conducting proper undersea search and rescue capabilities.

During the MERS outbreak, Pyeongtaek St. Mary's Hospital and Samsung Seoul Hospital were not able to handle the patient load. And major hospitals such as Samsung Seoul Hospital did not think they needed to notify the government unless someone actually tested positive for MERS. They did not communicate with relevant organizations efficiently. Furthermore, prior to June 15, 2015, MERS was not officially listed as an infectious disease in Laws pertaining to the Prevention and Management of Infectious Diseases (Ha, 2015).

The minister and vice minister of health and welfare are political appointees and acquire information about MERS through administrative professionals who specialize in health policy. They also have discussions with experts from the department that oversees disease control in Korea, but the director of this department has rather ambiguous authority when it comes to setting response agendas and guidelines related to quarantine. He does not possess equivalent authority to the surgeon general of the United States. The organization lacks authority as an independent control tower and this inevitably leads to limited on-site capabilities. During the MERS outbreak, a central MERS headquarters was established as well as a joint civilian-government task force. In the initial phase of the outbreak, the acting prime minister stated that MERS response measures would be carried out by Ministry of Health and Welfare alone, but the control tower in operation at the time did not have the authority to command a government-wide response. Both public and private health organizations designated their own directors to establish control towers, and they also cooperated with the department in charge of disease control. At this stage, the role of local governments 
and provincial and metropolitan governments was extremely critical. As the range of quarantine expanded, cooperation from local governments was necessary.

The government was harshly criticized for its management of the outbreak, although the criticism was not leveled primarily at the actions they prime minister took, who served as a control tower in his capacity as chairman of a centralized safety management committee. The Blue House formed a MERS emergency response team and the chief secretary of policy adjustment and the chief secretary of health and welfare served as co-chairs. Of course the president, Park Geun-hye, was designated as the head of this team, and she even postponed a visit to the United States to meet with her chief of staff, who had consulted with other chiefs before reporting to her. Other ministries and government organizations reported on their own as well. Later the Blue House hosted a joint civilian-government MERS-response conference so that information about how the crisis was being handled could be shared with the president. The president also visited departments throughout the government and ordered experts in each to move on managing the outbreak by tracking infection routes, establishing quarantines, and preventing additional infections. In conclusion, the role the experts played in this outbreak was important, but it is unclear what effect the president had acting as the control tower.

It was difficult for public health institutions to manage the outbreak since they only accounted for $10 \%$ of all health institutions. Pressure-relief mattresses as well as government and hospital experts were severely lacking in numbers. Local disaster and health crisis centers were absent. The handling of the MERS outbreak illustrates how hard it was for public health institutions to stop the spread of the outbreak (Song, 2015). More investment should be put into public health and more attention paid to it.

On-site officials' low rank and limited resources should be addressed as well. Safetyreviewing organizations tend to be institutions where retired government officials find reemployment, and as a result such organizations often lack sensitivity, independence, professionalism, and alertness. General disdain toward safety personnel in street-level bureaucracies should be addressed as well. In order to achieve this, it is critical to reverse the trend whereby only higher-level officials in a central policy institution have the authority to carry out directives. The control towers of local on-site safety organizations should possess the same authority as a director of any central organization. Recently, the government came up with a plan to divide the nation in four geographical jurisdictions and to put special SAR units in each area so that anywhere in the nation a SAR unit could reach a site within 30 minutes by land and 40 minutes by sea. The government could elaborate on this change by improving on-site crisis management.

It is important to note that civilian capabilities make significant difference on site. The safety policies of NGOs as well as companies and community-based organizations 
should be improved and supporting policies should be in place to effect such improvement. Transforming the public's attitude toward safety should likewise be a priority. Policies that reward people who take safety classes and training by deduct a certain amount from their insurance should be in place. Corporations that adopt safe business practices should likewise be rewarded. Additionally, expanding obligatory insurance policies for disaster prevention and response structures in businesses could be highly effective. Fines supplied and funds generated by corporations after crises are ineffective, so upgrading outdated facilities and investing in new safety equipment to prevent crises should be encouraged and supported. The government should be involved in the training of civilian crisis-response organizations and civilian relief organizations as well.

When it comes to areas in which expertise is considered extremely crucial, such as in preventing outbreaks out of infectious diseases, private health officials' opinions should be taken into account. This would be the most effective way to establish a cooperation system because $90 \%$ of all the hospital beds are privately owned, and local health centers and organizations fall under the jurisdiction of local governments. Furthermore, securing highly trained professionals with leadership skills is also important.

Professional positions being filled by administrative personnel owing to a job rotation policy could pose a serious problem in crisis management. For example, some positions in airport quarantine stations and organizations that communicate with first-line hospitals have been filled by administrative personnel rather than public health professionals. And even when these positions have been filled by public health professionals, these professionals are only given short-term contracts. Many staff members who work for the Korean Center for Disease Control and Prevention, for example, are contract workers who are supervised by administrative personnel. Such organizational structure is not a favorable environment for ensuring that professional decisions are made.

With respect to the very different kind of crisis that economic espionage, for example poses, it is also important to cultivate cybersecurity human resources. Some universities currently offer training in cybersecurity, but there are only few organizations hire them, and most of the training is only limited to reeducating employees already trained in data processing. New laws and regulations related to the promotion of the information security industry that will encourage organizations to hire more cybersecurity professionals are expected to be passed in the future, but incentives to attract talented prospective employees to this field are still lacking.

\section{Principle of Reporting First}

For managing crises in a bureaucracy, a principle of tightly coupled organizations has limited value. However, it is also difficult to overcome bureaucratic formalities 
where centralized bureaucratic traditions remain in place, such as the practice of reporting microscopic details and waiting for an order to be handed down to initiate action in order to avoid taking responsibility if something goes wrong. In other words, the principle of reporting first and acting later causes problems in the crisis management process. Devoting so much attention to the reporting of details conveys the impression of shunting legal, administrative, and moral responsibility.

The reporting-first principle can be reinforced by higher-level authorities. Many upper-management organizations often demand excessive reporting in order to avoid taking responsibility themselves. Such overdocumentation also stems from a lack of confidence on the part of on-site control towers in their own ability. Organizations try to hand off the chore of making assessments and decisions to higher organizations in the reporting hierarchy so as to reduce their burden. Take the military reporting system, for example. In the case of military crisis, spending too much time reporting the details of a situation to the government or the public and pushing off tactical decisions to an administrative-level control tower is not the best way to utilize military crisis management system. The president still has to occupy the control tower at the top in national security matters, but the professional assessment of staff in lower-level control towers, such as joint chiefs of staff, and their ability to take action without consultation is more important. The solution to this problem is clearly to assign authority and responsibility to on-site control towers.

\section{Communication Problems}

Although in cases of infectious disease outbreak, cyberattacks, and nuclear power facility accidents, experts' opinion is crucial not only in on-site management but also to the higher-level decision-making process in the government, most experts that are located on site experience various communication problems. The information these experts deliver to the higher level of organizations tends to be sketchy at best, and there are often information gaps and information-related failures. Simulation exercises are all well and good, but unless the various participants in them end up improving their communication skills, then well-preparedness will not be the result.

For example, nuclear safety measures are under the nuclear safety commission's jurisdiction. The commissioner, standing members of the various committees, staff, and experts as well as members of the nuclear safety control technology center have meetings to make decisions on nuclear-safety-related issues. The need for a control tower frequently comes up, especially because nuclear radiation safety requires an emergency response system. However, it is nearly impossible to report on-the-ground technical information to nonexperts accurately, and it is equally difficult challenge to 
accurately relay such information to the media and to set up safety guidelines for the public. The Three Mile Island accident in the United States, the Chernobyl incident in Russia, and the breach of three reactors at Japan's Fukushima nuclear power plant all exposed problems in communication of nuclear power plant safety issues and in the decision-making processes connected to these issues. The Three Mile Island accident, the least serious and the best-documented nuclear power plant accident, revealed the kind of communication problems that can occur during a crisis between on-site personnel and a control tower staffed by nonexperts (Walker, 2004). Moreover, if an incident is severe enough to require civilian evacuation, successful communication among experts, administrative personnel, and the public becomes critical. If experts are to gain the trust of the government and the public, their advice needs to be heeded. Every control tower should have plans to develop tools that enable experts to communicate with nonexperts and that allows it to maintain a systematic relationship with the media.

During a crisis, panic, disorder, and confusion tend to prevail on site and the survival instinct kicks into gear, so without careful preparation and the ability to adapt to changing circumstances quickly, damages can be greater than they would be otherwise. A postbureaucratic networking structure and the basic principle of a symphony orchestra could help address these problems. In a postbureaucratic organization, on-site control towers possess full authority, which encourages participants' self-organization and creativity (Roberts \& Lajtha, 2002).

On-site control towers should ask higher decision-making control tower to authorize support from organizations out their mobilization zone, and higher-level control towers should also provide support from external organizations at each stage of a crisis and limit their role to clarifying relationships among existing control towers and support organizations. An out-of-date emergency organizational arrangement, difficulties gathering essential information, and a vulnerability to unproductive debate that tends to slow down or derail problem solving during time of crisis are real problems. A tightly coupled control tower system at the macro level discourages creativity, innovation, flexibility, and adaptation.

\section{Incident Command System (ICS)}

Common characteristics of on-site crisis scenes that pose safety threats are panic and strategic uncertainties that arise from the uncoordinated actions of multiple organizations with different backgrounds. Actors from different government agencies and private sector cannot coordinate their rescue activities easily. Some first responders are voluntary and can leave if their demands are not met. Collective decisions depend on 
consensus rather than on the giving or receiving of orders from a central authority (Powell, 1990).

For this reason, there has been an effort to systemize the ICS (incident command system), an emergency rescue team that is meant to be largely modeled on U.S. fire response plans (Kikuen Yang, 2008). Even though military culture tends to provide the foundation for organizations in Korea, participants in the rescue operations of the Sewol and Sampoong department store accidents have testified that operations were executed in an ironically disordered fashion. Models ought to be designed based on real on-site scenarios rather than on documents and reports, control tower personnel should be appointed who have professional credentials in the area the control tower will be overseeing, and realistic simulations based on control systems theory should be designed and executed to improve the capabilities of the staff. Each model and simulation designed should have specific SOPs (standard operating procedures) that are periodically updated. On-site control systems in each field should utilize visual informational communication technology to design e-ICS to be used in education and training. Using realistic ICS models to survey lacking resources is also needed. These procedures will provide a foundation for an on-site-centered ICS paradigm. Administrative control towers will likewise benefit in the process of aiding ICS.

Civil defense exercises based on civilian defense law continue to improve since they were first introduced in 1975. They now encompass every response measure to crises and disasters. Each part of the civil defense system, which is overseen by the Civil Defense Council chaired by the prime minister, such as planning, the designing of countermeasures, rescue, and the management of agricultural disasters, are systematically divided among respective ministries of the government. Training is carried out on 15 th of every month to ensure the system is operating at peak efficiency. Further efforts to assign specific disasters to the ministries that would best know how to handle them as well as developing additional countermeasures are necessary. Moreover, developing scenarios for simulation training in each field is needed in order to assign expert organizations to specific potential crises. Last, all relevant control towers should participate in exercises and simulations, and higher-level administrative control towers should be discouraged from using their hectic schedules as an excuse for putting off participating in them.

A crisis requires the mobilization of multiple entities that differ in nature. The closest to the crisis are the individuals facing it, followed by various civilian groups and organizations. For example, hospitals, banks, factories, and local communities are at the forefront of most crises. The networks across local governments, the departments of the central governments, and ultimately the Central Countermeasure Headquarters must respond effectively to those at the forefront. When it comes to integrating the 
efforts of civilian volunteers, government agencies, and private sector companies through intelligence sharing and a division of tasks, a military-style command system and leadership befitting of more homogenous organizations will have its limits. This is especially true during the early stages of a crisis, when the severity and extent of it is unknown. Rather, the entire system must be managed flexibly to ensure voluntary participation of the component organizations, which will help accelerate collaboration and thereby enhance performance. Instead of higher-level administrative organizations issuing orders to subordinate organizations, there should be an effort to build and manage partnerships across differing organizations. Professional expertise affects every aspect of crisis management, especially in the case of nuclear power facility accidents, cyberterrorist attacks, and infectious disease outbreaks. In order to strengthen on-site control systems, therefore, experts should be afforded both greater authority and status. It is common to see experts in low-ranking positions in public sector. Their ability to leader and establish relationships with external organizations is frequently doubted by those in traditional bureaucratic circles. The solution to this problem is to train experts in the organization. What makes flexible coordination possible is a devolution of authority toward on-site expert control towers.

\section{ADMINISTRATIVE CONTROL TOWER PROBLEMS AND SOLUTIONS}

In crisis management, the line between the on-site control tower and the administrative-level command and control tower may often be blurry, which makes it all the more essential in the case of national crises that the two relate in a seamless and flexible way. While this paper conceptually distinguishes between on-site and administrative control towers, in reality the two are interconnected. The functioning of administrative control towers could be improved by undertaking an assessment of the policy- and decision-making structure of the higher level of the national crisis management system (NCMS) in terms of legal structure, the different roles of the president and the prime minister, and the decentralized or loosely coupled cooperation system of relevant government organizations.

\section{Legal Structure}

The constitution of the Republic of Korea establishes the key roles of the president in crisis management. Articles 72, 73, 74, 76 and 77 of the constitution clearly indicate that the president is to serve as the control tower during domestic and foreign calamities, 
natural disasters, and financial and economic crises. The constitution only explicitly refers to the topmost portion of the control tower, and the lower levels of the control system are much more complex and differ depending on the nature of the crisis. The National Security Council develops key policies and the National Security Office oversees practical implementation. What falls under the umbrella of national security is a contested issue, but the state of the divided Koreas has rendered guarding against threats posed by North Korea a key aspect of national security.

The Framework Act on the Management of Disasters and Safety stipulates that the Ministry of Public Safety and Security is in charge of responses to human disaster, fires and natural disasters, and maritime disasters, distinguishing this system as one separate from national security. There are currently limitations to how much this system can handle, however, when it comes to issues such as energy, climate change, water resource, and financial crisis, and significant changes to manpower allocation are needed if the system is to be able to respond to such problems. It is clear that the National Security Office can exercise its role as a control tower in only limited range of areas. In areas such as diplomacy, the reunification of the two Koreas, and other macroscopic fields of national security, it is more appropriate for the president to serve as the control tower, and a certain degree of centralization is called for in these areas. In order to ensure that the president-who is not necessarily an expert in them-is able to provide guidance, the advisory function of each area and the responsibilities of supporting bodies should be clearly stipulated. There needs to be a device that can help overcome the bureaucratic tendency to seek to evade responsibility that results in the president having to make decisions even the case of very technical matters.

With respect to the role of the prime minister, Article 86 stipulates that "the Prime Minister shall assist the President and shall direct the Executive Ministries under order of the President," meaning that unlike in the area of national security, at the order of the president the prime minister can assume control over a broader range of issues connected to human disasters. Even in absence of an explicit presidential order, the prime minister may arbitrate the task of the administrative branch in accordance with the Government Organization Act. This task is undertaken by the director of the Office for Government Policy Coordination. The Government Organization Act describes the organization necessary for consistent and systematic execution of national affairs and the tasks that departments connected with national affairs are responsible for and makes the administrative branch a component of the system that manages the crisis. Related regulations also lay out in detail which government organizations become active at which phase in a given crisis. This is also laid out administratively as policy, each organization having its own SOP. The prime minister, for example, assumes the role of director of Central Countermeasure Headquarters during a large-scale disaster. 
The position of secretary of disaster safety was also established at the Blue House as way of liaising with and briefing the Office of the President and for receiving orders from the president. However, the prime minister is defined as the de facto control tower for crisis management, although the prime minister always reports to the president, and the president issues his or her orders to the prime minister. Furthermore, that the prime minister is the de facto control tower during crises does not necessarily mean that the president cannot become the control tower as well. If the need arises, the president can always serve as the control tower as the president is at the top person in charge of state affairs in a presidential system.

Newly established by the Park Geun-Hye administration, the Ministry of Public Safety and Security is directly subordinate to the Office of the Prime Minister. It serves as the working-level control tower in the response system that responds to disasters and that oversees safety and recovery. Responsibility for Human disasters, fires and natural disasters, and maritime disasters has been integrated into the other responsibilities of the Ministry of Public Safety and Security. While some consider the National Security Office to be the upper-tier level and the Ministry of Public Safety and Security to be the lower-tier level of the NCMS (Kim, 2012), there is no need to view one as being higher than the other; instead, the two bodies can be understood as just having different roles. The Ministry of Public Safety and Security oversees the integrated planning for responding to disasters and ensuring safety. Its areas of responsibility include emergency preparation, civil defense, fire safety and disaster prevention, and maritime safety and incidents. Through the Special Disaster Office, the Ministry of Public Safety and Security also oversees responses to disasters categorized as special disasters, including disasters related to aircraft, energy, gas, explosives, communication, and infrastructure.

The Blue House serves as the control tower when it comes to responding to cyberterrorism and hacking. The government established comprehensive countermeasures against them after such incidents as the March 20, 2013, cyberterrorist attack on financial institutions and broadcasting companies and the June 25, 2013, hacking of the computers in the Blue House and Saenuri Party offices. The "Comprehensive Solution for National Cyber Security," released on July 4, 2013, reveals that in the case of cyber crises, the Blue House (National Security Office) assumes the role as the top control tower, while the National Intelligence Service (NIS) serves as the control tower for working-level activities. The Cyber Safety Center of the NIS is such working-leveloriented organization. While North Korea is often behind cyber attacks in South Korea, there are also many other cyber security mishaps. According to a report by IBM, South Korea ranks third in the number of cyber security incidents (IBM, 2015). South Korea also ranks in the top three for malicious code infections (CCM) according 
to a Microsoft security intelligence report. Cybersecurity remains an uncertain area despite the research being undertaken and preparations being made by the National Security Research Institute under the Ministry of Science, ICT, and Future Planning, the Korea Internet and Security Agency, the Ministry of National Defense, the Korea National Police, and the NIS.

Since cybersecurity is a specialized field with a technological foundation, it is essential that experts in the NIS and in other areas can collaborate without the organizational culture acting as a barrier. Although NIS is represented as the cybersecurity control tower in South Korea, it is important for the government and civil organizations that have fallen victim to cyberhacking and terror to work to prevent and defend against recurrences, and so any department that becomes a cyber target should report simultaneously to the Blue House (National Security Office), NIS, and the head of the relevant central administrative body (Kim, 2014). If they do, then collaboration between organizations that have both expert personnel in the field and a professional response team is more likely to occur. If the severity of the situation requires, the president could also be briefed by relevant offices and through the Blue House chief of staffs be asked for directives.

\section{The Relationship between the President and the Prime Minister}

The president's deeply involvement in a given crisis can serve to mobilize government officials for duties, but it does not necessarily guarantee a flexible response. The early involvement of the Blue House may contribute to the public perception of stability through the media since it can suggest that the president is in control of the situation. However, such involvement can also subject the Blue House to criticism from the media and the public, especially when minor on-site handling is not effective in practice.

Although the constitution defines the authority and responsibilities of the prime minister and the Office of the Prime Minister in crisis management, these need to be elaborated. In fact, arbitration and supervision are tasks with blurry boundaries. While quotidian duties may be undertaken by the Office of the Prime Minister in accordance with the authority granted by the constitution and the Government Organization Act, the range of authority and responsibility, not to mention the nature of the prime minister's role in the various national crises, remain unclear. In the early stages of a crisis, the prime minister's position is ideal for appealing to the public on behalf of multiple government ministries, for mobilizing civilian experts and volunteers, and for gaining cooperation from local governments. Because the prime minister is able to see the entire government alongside the president and discuss matters of national affairs with the resident, the prime minister can share key duties with the president. 
Article 86, paragraph 2, of the constitution stipulates that the "Prime Minister shall assist the President and shall direct the Executive Ministries under order of the President." The presidential order may be specific or general. It would be helpful if each new administration would clarify the role the president will play as the control tower in crisis management and in addressing the problem of chronically stagnant national affairs. In order for the prime minister to improve in his or her role as a control tower, several issues must be addressed. The first pertains to the prime minister's ability mobilize the military. The extent of the prime minister's right to issue directives to the minister of national defense and to exercise military control over the joint chiefs of staff needs to be clarified. In fact, only the president has explicit authority to issue military directives as the commander in chief. To cope effectively with a crisis such as the sinking of the Sewol, when the on-site control tower is not able to mobilize the military, it must be established which body in the upper echelons of the central response organization can assume the role of the control tower that calls in the military. Next, there is the question of how deeply the Blue House secretariats will be involved in the Countermeasure Headquarters meetings led by the Prime Minister. During the SARS outbreak, the active role of the prime minister proved effective (Goh, 2013). Even under today's constitution and legal structure, it is possible to make use of the method of mobilization employed Prime Minister Goh Kun during the SARS epidemic. At the time, the medically affiliated portion of the military was mobilized to supplement and support public medical services. Although it is unclear if there was written exchange with the president, the fact that the Countermeasure Headquarters mobilized the military shows that the prime minister was the de facto highest in the chain of command. The fact that Ministry of National Defense committed its personnel to the crisis even though the Ministry of Health and Welfare has no legal authority to mobilize the military revealed the hierarchical nature of the control tower system in that the control tower beyond the minister level managed to secure support that would have been impossible for control towers at a lower echelon to secure. Moreover, the fact that the Blue House chief of staff and senior secretary was invited to join the National Affairs Policy Steering Commission indicates that the prime minister has in effect managed to assume control of the coordination of national affairs. In a Blue House-centric government, the prime minister may sometimes be left out of decision making. However, when the prime minister takes the lead, sets the topics for discussion, and invites the Blue House staff to the discussion, it is evident that the prime minister has more room to act as a de facto control tower.

This reflects the trust between the president and the prime minister, leading the ministers to respond more enthusiastically to the prime minister. This kind of setup demonstrates the president's leadership in a crisis while also reflecting the national 
affairs management capacity of the president. Moreover, placing the Office of the Prime Minister at the center of interministerial cooperation reduces the load on the president while enabling the prime minister to proactively spearhead government administration and thereby enhance government efficiency. Granted, this expands the authority of the prime minister in areas such as defense, security, intelligence, and public order, and thus requires a clear confirmation from the president regarding the division of administrative duties. Some areas may be more difficult to delegate. For example, cybersecurity is directly linked to national and military security and falls under the responsibility of the NIS. Delegating supervision of such matters to the prime minister could be risky, as the prime minister is limited in his or her capacity and authority when it comes to security and controlling the duties of the NIS.

\section{Elastic Collaboration System}

Because the control tower operation features a high concentration of power and command authority, a poorly designed and rigidly operated control tower will be inefficient and likely to make mistakes. The expertise of varying areas and response capabilities must be flexibly integrated into the array structure of the control tower. A flexible system is one wherein all organizations, including small on-site civilian community organizations, on-site government response teams, minister-level central countermeasure organizations, and even the president have autonomy, an appropriate level of local discretionary authority, and the capacity to actively address the magnitude of the situation. A balance between rigidity and flexibility is essential for success.

Global optimization, a process in which the president attempts to control every system, is inefficient. If at all possible, it is better to pursue local optimization. Control towers should also be designed and operated in a way that allows for a more elastic management method, one that enables talent to flourish and that elicits enthusiasm and integrative energy. The institutional uncertainties that arise from the difficulties of coordinating actors and administrative organizations can be addressed by developing shared leadership among participating organizations (Moynihan, 2008).

Practical response and recovery measures should be handled by the heads of each respective department best suited to handle a given situation. As resources for arbitrating issues across the Ministry of Public Safety and Security and the Office of Prime Minister are committed, the Blue House should provide direction and make final decisions. Concentrating too much power in the top administrative control tower can cause chaos, delays, confusion, and failure. The bowing down to centralization that tends to underpin Korean bureaucratic practices must be eliminated. No organization or system is omniscient, and no two crises are identical. 
Although it is difficult to apply either cabinet-centric or Blue House-centric approaches in all situations, the goal should be for the Blue House to save its energy for matters of diplomacy, defense, and national affairs. If the control system for special crises has been designed in such a way as to be cabinet-centric and has been subjected to sufficient prior simulated exercises, the Blue House will be able to focus more on the unique duties of the president. For example, right before the Korea-U.S. summit, the incidence of MERS seemed to be on an uptick. Had the prime minister or the vice prime minister actively stood up in the control tower alongside cabinet ministers, the president could have proceeded with the trip to the United States. Although the issue of the visit to the United States did end up being a point of contention, the public accepted the decision, and criticism was mild when the president delayed the trip in order to assume the role of the MERS control tower. This incident demonstrated a facet unique to Korean political culture. Nevertheless, the president's assumption of the role of the MERS control tower was symbolic, and it did not lead to any presidentiallevel decisions, nor did it contribute to the mobilization of more powerful and creative resources. The president's presence cannot be said to have produced an optimal response to the crisis.

In administrative-level crisis management, there should be a greater emphasis on the principle of explicitness to clarify the roles and responsibilities of the Blue House and the cabinet, the prime minister and cabinet ministers, ministry-level organization, local governments, and public corporations. Elastic management is a challenge for bureaucratic organizations based on hierarchy and authority, but reform is necessary. In particular, the relationship between central and regional governments must be improved. The clash of political parties and interests between central and local governments has resulted in a fiasco that rears its head even during crises. While it is indeed the responsibility of the Office of the Prime Minister to arbitrate conflict between central and regional governments, the president also has a role to play when it comes to building cooperation. There is only so much the Ministry of the Interior can do on its own. The prime minister too must become one of the pillars for integrated centralregional relations. When a crisis climaxes to a point where local governments and civilian contribution becomes essential, if communication from the site to the final decision makers is seamless and expeditious, the leadership is strong, resources have been effectively committed, and decision-making systems are expeditious, then the crisis management system will earn credibility in the eyes of the public (Bea, 2007). The president's role is to ensure the credibility of the response and control system, and elastic management and expertise are key factors in establishing such credibility. 


\section{CONCLUSION}

The prevalence of media reports and previous studies regarding expectations for a President-centric control tower in connection with state affairs has two implications. First, it suggests that the legacy of past president-centric governance has given rise to the widely accepted idea that presidential orders alone provide the key to effectively solving problems. Such a notion demonstrates the inertia and path dependence that has followed Korea's emergence as a developmental state. Second, it suggests that the civilian sector as well as government organizations have been so decentralized that it has led to a state of hyperpluralism and that a sophisticated arbitration mechanism and transformational leadership are necessary to make collaboration possible. The unilateral orders and control methods of the past no longer work. Despite this, there may also be a regressive attachment to the idea that the president must lead the way, and a rejection of the notion that we should develop new methods of governance and management.

Whatever the cause of the attachment to the president-centered vision of the control tower, the president cannot function as the control tower for every aspect of every crisis. In order for the president to fulfill the role of head of the government, it is essential that the prime minister, ministers, local governments, public institutions, businesses, and civil organizations establish autonomous policies and cultures to prevent and respond to crises. A closely controlled system poses more barriers to mechanisms of self-organization. Seeking a balance between a rigidly controlled system of organizations and a loosely coupled system is the alternative. In a pluralistic array of organizations, no single organization can be expected to manage every aspect of a situation; rather, responsibilities must be shared depending on the function of each organization.

Elastic crisis management, which depends on a balance between rigidity and flexibility, remains a puzzle for Korean administration. Some argue that a variety of administrative intermediaries should be established and that a new kinds of administrator is required (Kettl, 2002, pp. 151-171) While administrators accustomed to a traditional command-and-control-type system are necessary in a certain areas of government departments, in other areas, the system should incorporate openness, flexibility, and creativity. Given that governance has become more open, that the system that provides administrative service has become more pluralized, and that collaboration across government organizations and the role of civilian sector has expanded, it is necessary to secure new talent that is capable of managing diverse networks even under the pressure of a crisis.

Lastly, it is important for control towers to consider developing and implementing post-crisis policy changes. Following a crisis, a so-called white paper is published that outlines problems and recommends improvements. Often such publications are used 
as a strategy to restore the image of a department whose reputation was damaged owing to poor handling of a crisis or to diffuse public dissent. Countless reports and after-action measures drafted after each incident lay dormant in archives. This is one of the notorious weaknesses of the Korean government. Many policies also end up neglected when the tenure of the organization head expires or when the administration changes. Oblivion is the greatest form of escapism. The need for investment is ignored, and the lessons learned for improving the operation of control towers are not made public. Control towers that can implement lessons learned from large-scale disasters and crisis management will play a decisive role in restoring faith among the national populace.

\section{REFERENCES}

Bea, K. 2007. Federal emergency management policy changes after Hurricane Katrina. Washington, DC: U.S. Congressional Research Service.

Bentz, B. 2014. Supply-chain control towers help organizations respond to new pressures. Supply Chain Management Review, 18(4): 34-47.

Goh, K. 2013. Tales I want to leave behind. Joong Ang Ilbo, February 28.

Ha, H. 2015. Reasons for reforming South Korea's health administrative system. Korea Policy Forum, 150(18).

IBM. 2015. X-Force Threat Intelligence Quarterly, March 3.

Kang, O., \& Park, H. 2014. A review of control tower manuals in response to marine disasters. Marine Logistics Research, 30(4): 897-918.

Kettl, D. F. 2002. The transformation of governance. Baltimore, MD: Johns Hopkins University Press.

Kikuen Yang. 2008.

Kim, C. 2008. The need for a national-level control tower in science and education. Science and Technology, 41(11): 100-101.

Kim, J. H. 2014. A study on the establishment of a cybersecurity control tower from a constitutional perspective. MA thesis, Koryo University.

Kim, M. K. 2012. A metagovernmental study of the national crisis management system. Crisis management, 8(5): 53-82.

Kim, S. 2011. The Republic of Korea's ocean policy: The need for an integrated control tower. Ocean Korea, 11.

Ministry of Public Safety and Security. 2014. Disaster report.

Moynihan, D. P. 2008. Learning under uncertainty networks in crisis management. Public Administrative Review, 68(2): 350-365. 
Park, S., Ko, C., \& Kim, J. H. 2012. Proposal to establish an IT control tower for information technology and content integration for the next administration. Digital Policy Research, 10(1).

Powell, W. W. 1990. Neither market nor hierarchy. In B. M. Staw \& L. L. Cummings (eds.), Research in Organizational Behavior, vol. 12 (pp. 295-336). Greenwich, CT: JAI Press.

Roberts, B., \& Lajtha, C. 2002. A new approach to crisis management. Journal of Contingencies and Crisis Management, 10(4): 181-191.

Schlesinger, A. M., Jr. 1973. The Imperial presidency, Boston: Houghton Mifflin.

Seidman, H. 1998. Politics, positions, and power. New York: Oxford University Press.

Song, K. 2015. Lessons from MERS. Korea Policy Forum, 150(16).

Walker, J. S. 2004. Three Mile Island: A nuclear crisis in historical perspective. Berkeley: University of California Press and U.S. Nuclear Regulatory Commission Library. 